Agro-Science Journal of Tropical Agriculture, Food, Environment and Extension Volume 19 Number 2 (Apr. 2020) pp. $41-47$

ISSN 1119-7455

\title{
INFLUENCE OF PRIOR FEEDING EXPERIENCE AND FOOD DEPRIVATION ON FLOUR SELECTION AND UTILIZATION BY THE RED FLOUR BEETLE, Tribolium castaneum (Herbst)
}

\author{
${ }^{* 1}$ Ojumoola A.O., ${ }^{1}$ Obikwe E., ${ }^{2}$ Oladigbolu A.A. and ${ }^{1}$ Adesiyun A.A. \\ ${ }^{1}$ Department of Crop Protection, University of Ilorin, PMB 1515, Ilorin, Nigeria \\ ${ }^{2}$ National Horticultural Research Institute, P.M.B 5432, Idi-Ishin, Ibadan, Nigeria \\ *Corresponding author's email: ojumoola.oa@unilorin.edu.ng
}

\begin{abstract}
The influence of prior feeding experience and food deprivation on selection and utilization of wheat flour (WF), melon seed flour (MSF) and mung bean flour (MBF) by Tribolium castaneum reared on WF was investigated in this study. Flour selection, measured by percentage gravitation and acceptance of the flours by beetles (when fed and also when starved for 48 hours), was studied in choice and no-choice tests. On the other hand, T. castaneum's utilization of flours for growth and development was determined by monitoring population changes for three months in each flour type infested with 10 beetle pairs. Results of three-flour choice tests showed that gravitation (55.56\%) and acceptance $(54.44 \%)$ were significantly higher $(p<0.05)$ in WF than MSF and MBF. Also, MBF significantly ( $p<0.05)$ had higher beetle gravitation $(80.56 \%)$ and acceptance (72.78\%) than MSF in a two-flour choice test. In no-choice tests, percentage gravitation and acceptance of beetles to the control (no flour situation) was significantly lower $(p<0.05)$ compared to MBF. Selection of MSF by T. castaneum was, however, not significantly different $(p>0.05)$ from the control in the study. Flour utilization followed a similar trend with significantly higher $(p<0.05)$ mean adults and larvae numbers in WF (211.33, 81.33) and MBF $(87.67,31.00)$, respectively compared to MSF $(28.33,7.67)$ at three months after infestation. The study concluded that flour selection in T. castaneum is influenced by prior feeding experience but not by food deprivation status of the beetles. Flour utilization is, however, neither influenced by prior feeding experience nor by food deprivation.
\end{abstract}

Key words: Tribolium castaneum, host range, choice test, no-choice test, flour

\section{INTRODUCTION}

The rust red flour beetle, Tribolium castaneum (Herbst) (Coleoptera: Tenebrionidae) is a cosmopolitan insect pest (Shafique et al., 2006) whose adult and larvae stages cause direct feeding damage to broken grains or nuts in storage (Applebaum, 1969; Johnson, 2013) and contaminate flours and other stored products with toxic secretions and exuviae (Villaverde et al., 2007; Johnson, 2013). In Nigeria, T. castaneum infests a wide range of flour products including those obtained from cereals like wheat, sorghum, millet, maize and acha; pulses like cowpea and groundnut; oil seeds like benniseeds as well as yam, cassava and other root and tubers crops (Hill, 1983, Lale and Yusuf, 2001; Bulus, 2008; Kayode et al., 2014).

To develop effective management strategies for T. castaneum, detailed laboratory studies are often carried out on its biology, sensitivity to toxicants and host range amongst others. Host range or host preference studies are aimed at identifying the different host plant species that can support complete development of a given insect (Bernays and Chapman, 1994; Schaffner, 2001) usually in choice or no-choice tests (Van Driesche and Murray, 2004). In a choice test, two or more potential host plant species is usually offered simultaneously to an insect, while in no-choice tests only a host is presented (Van Driesche and Murray 2004). Host range studies often require large numbers of the test insects thus necessitating continuous rearing on a suitable substrate. Consequently, such studies usually entail culturing test insects for one or more generations on a single host type in order to obtain enough insects. Unfortunately, the use of insects reared on a particular plant host may result in a prior feeding experience bias for that host in choice tests leading to a false negative - a situation where an insect fails to accept a suitable host for food because of the presence of a more familiar one (Withers and Mansfield, 2005). Also, insect parasitoids usually have a bias for the host or plant-host complex they experienced during rearing or previous laboratory trials (Withers and Mansfield, 2005). Apart from prior feeding experience, another factor that may negatively affect the results of host range tests is food deprivation. It has been reported that the 
probability of an insect accepting a host as food increases as its period of food deprivation increases (Barton-Browne and Withers, 2002; Withers and Mansfield, 2005). Thus food deprivation may lead to a false positive - a situation where an insect accepts a non-host for food in a no-choice test.

Laboratory rearing of $T$. castaneum beetles for host range studies is usually done on flours milled from cereals with wheat flour being commonest (Applebaum, 1969; Tamgno and Ngamo-Tinkeu, 2014; Kayode et al., 2014; Yan et al., 2017). To ensure the reliability of results obtained from host range studies of stored product insects, there is the need to determine the extent to which prior feeding experience and food deprivation influence host selection and utilization. The present study was thus aimed at investigating the influence of prior feeding experience with wheat flour and food deprivation of adult $T$. castaneum beetles on the selection of wheat flour (cereal), mung bean flour (legume) and melon seed flour (Cucurbitaceous vegetable) in a series of choice and no-choice tests. In addition, the ability of beetles to utilize each flour type for growth and development was investigated in a population dynamics study.

\section{MATERIALS AND METHODS}

\section{Study Site}

The laboratory study was carried out at the Department of Crop Protection, Faculty of Agriculture, University of Ilorin, Ilorin, Kwara State, Nigeria $\left(8.50^{\circ} \mathrm{N}, 4.68^{\circ} \mathrm{E}\right)$ under ambient laboratory conditions $\left(27 \pm 2^{\circ} \mathrm{C} ; 70 \pm 5 \%\right.$ relative humidity and $12: 12 \mathrm{~h}$ photoperiod).

\section{Source, Type and Sterilization of Flours}

The flour types used in the study were wheat flour, mung bean flour and melon seed flour. Wheat flour (Honeywell brand) was purchased from Kenyatta market, Uwani Enugu, Enugu State, Nigeria. Melon seed flour used in the study was obtained by milling air-dried melon (Cucumis melo L.) seeds with an Electroline Maxwell blender. The NHCmKn-1 accession of melon seed used in this study was obtained from the National Horticultural Research Institute (NIHORT), Ibadan, Oyo State, Nigeria. The seeds were small, light brown, smooth, $0.4-1.1 \mathrm{~cm}$ long and 0.2-0.3 wide. Similarly, mung bean flour was obtained by milling mung bean (Vigna radiata $\mathrm{L}$.) seeds into fine powder using the blender. The SMH 888 variety of mung bean seeds used was small sized with green seed coat. The seeds were obtained from the Department of Agronomy, College of Crop and Soil Science, Michael Opara University of Agriculture, Umudike, Abia State. Before use, flours were stored in a freezer (Thermocool-250 refrigerator model) for 2 days at $0^{\circ} \mathrm{C}$ to disinfest them of any insect.

\section{Proximate Analysis of Flour Types}

The percentage moisture, crude protein, ether extract, ash and crude fibre contents in samples of each flour type were determined by proximate analysis using the procedure described by the Association of Official Analytical Chemists (AOAC, 2010). Percentage Nitrogen Free Extract (NFE), which includes soluble carbohydrates like starch and sugar, was determined by subtraction. Proximate analysis was conducted at the Central Research Laboratory, University of Ilorin, Ilorin, Nigeria.

\section{Culture of T. castaneum}

Population of $T$. castaneum that had been maintained for several generations on wheat was obtained from the Nigerian Stored Product Research Institute (NSPRI), Ilorin, Nigeria. Fifty pairs of adults were taken from this parent population and introduced into four different plastic jars each of size $11 \mathrm{~cm}$ by $11 \mathrm{~cm}$. Each jar (with about 25 adult beetles) was half filled with sterilized wheat flour and thereafter covered at the mouth with a piece of muslin materials to allow for ventilation. The jars were left on the laboratory bench for 12 days after which all adults (dead or alive) were sieved out. The adultfree flour in the jars was thereafter checked regularly for newly emerged adults.

\section{Experiments and Experimental Procedures Effect of prior feeding experience and food deprivation on selection by $\boldsymbol{T}$. castaneum}

Effect of prior feeding experience and food deprivation on selection by $T$. castaneum The effects of prior feeding experience and food deprivation on flour selection by $T$. castaneum adults were investigated in a number of experiments namely - choice test I, choice test II, no-choice test I and no-choice test II. Each test was conducted within an arena made from flat circular stainless trays $(29 \mathrm{~cm}$ by $4 \mathrm{~cm}$ ) that had been divided into sectors on the inside (Figure 1). Choice test I was a three-flour experiment with four treatments namely - wheat flour (WF), melon seed flour (MSF), mung bean flour (MBF) and a control treatment without flour. The choice test I was thus carried out in an 8sector (45 degrees each) arena with two sectors allocated to each treatment. Arena for choice test II (a two-flour experiment) on the other hand had 6 sectors (60 degrees each) with two sectors allocated to one of the three treatments -MSF, MBF, and the control. No-choice tests I and II were one-flour tests that included the control and either MSF or MBF. No-choice tests were consequently evaluated in 4-sector (90 degrees each) arenas. In both choice and no-choice tests, 2-3 days old $T$. castaneum beetles, which were not deprived of food before each test, were used. Thereafter, the tests were repeated using beetles that had been deprived of food for $48 \mathrm{~h}$ before tests commenced. 


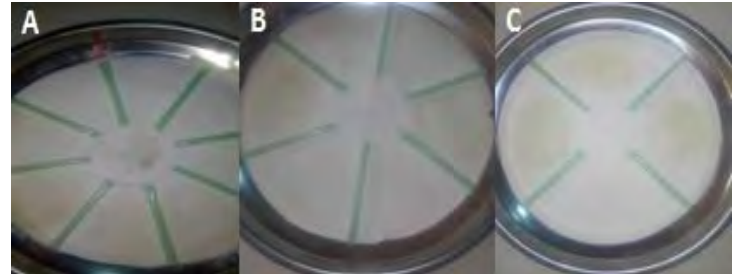

Figure 1: Experimental arena with 8 sectors (A), 6 sectors (B) and 4 sectors (C)

Furthermore, in the choice and no-choice tests, selection of flour types was measured at two distinct phases, i.e., gravitation to flours by adult beetles and acceptance of flours by the beetles after gravitation. Beetles were said to have gravitated towards a given flour type if they had moved into the sector(s) containing the flour and were actively probing its surface at the end of each observation period. Acceptance of a given flour type by $T$. castaneum beetles, on the other hand, occurred only when they had burrowed and settled within the flour.

\section{Choice and No-Choice Tests}

In choice test I, two sectors in the 8-sector arena were randomly selected and each filled with $2 \mathrm{~g}$ of WF, MSF or MBF flours. The remaining two sectors were left empty as the control. Thirty unsexed adult $T$. castaneum beetles that had been well fed just before the experiment were introduced into the centre of the arena and allowed to make their choice of flour. The arena tray was covered securely with another tray of the same type and the set up left for $24 \mathrm{~h}$. Thereafter, data was collected on the percentage number of adults that gravitated and accepted each flour type. The experiment was again repeated with 30 adult beetles that had been deprived of food for $48 \mathrm{~h}$. The choice test I with and without food deprived insects was done using a Completely Randomized Design replicated three times. Choice test II was conducted to remove any bias for WF that might have led to a false negative response to both MSF and MBF in choice test I. Choice test II was thus conducted using a 6-sector arena and as before, two sectors each were randomly selected and filled with $2 \mathrm{~g}$ of MSF and MBF. All other procedures on set-up and data collection were followed as in choice test I. Selection of MSF and MBF by $T$. castaneum beetles were assessed separately in no-choice test I and II respectively using a 4-sector arena. In each no-choice test, two sectors were selected randomly and filled with $2 \mathrm{~g}$ of flour while the remaining two were left empty as control. Other procedures on set-up and data collection earlier described were followed.

Utilization Test of Flour Types by $T$. castaneum The utilization of WF, MSF and MBF by $T$. castaneum for growth and development was studied in a population dynamics experiment laid out in a Completely Randomized Design. Thirty grams (30 g) of each flour type was weighed into a plastic container, $4.6 \mathrm{~cm}$ by $11.6 \mathrm{~cm}(350 \mathrm{ml})$, after which 10 pairs of adult $T$. castaneum were introduced into them. Each treatment was replicated 3 times and left on the laboratory bench. Data on population changes of adults and larvae within each flour type was taken every month for three months.

\section{Data Analysis}

Data on percentage number of adult beetles that gravitated and accepted each flour type during the choice and no-choice tests were subjected to a twoway analysis of variance with flour types and food deprivation as factors. In contrast, data on population dynamics was subjected to a one-way analysis of variance. Mean separation, where necessary, was done with Tukey's honestly significant difference at 5\% significance level. All statistical analyses were carried out using the IBM SPSS version 20 software.

\section{RESULTS}

Significantly higher $(p<0.05)$ mean percentage gravitation $(55.56 \%)$ and percentage acceptance (54.44) of $T$. castaneum adults were recorded for WF than for MSF or MBF in choice test I (Table 1a). Similarly, percentage of adults that gravitated $(35.56 \%)$ and accepted (35.00\%) MBF was significantly higher $(p<0.05)$ than that of MSF or the control. No significant $(p>0.05)$ differences were however observed in the percentage of adults that gravitated and accepted MSF and the control. Food deprivation did not have any significant effects on percentage gravitation and acceptance of flours by beetles at $p<0.05$ (Table 1b).

Significant interaction effects were observed between flour types and food deprivation in choice test I (Table 1c). Compared to other treatment combinations, a significantly $(p<0.05)$ higher percentage $(65.56 \%)$ of adults deprived of food for 48 hours gravitated towards WF with an equally significant percentage $(65.56 \%)$ of the beetles accepting it. In contrast, the least percentage gravitation values $(3.12 \%$ and $1.11 \%)$ observed in the control differed significantly from all other treatment combinations. In addition, the percentage of adult $T$. castaneum that accepted MSF did not differ significantly $(p>0.05)$ from those that accepted the control at all levels of food deprivation. Whether food deprived or not, the percentage of adults $(30.00 \%$ and $41.11 \%)$ which gravitated towards MBF (30.00\%) and which also accepted it $(40.00 \%)$ did not differ significantly $(p>0.05)$ from the percentage of non-food deprived adults which gravitated and accepted WF.

Similar trends observed in choice test I also played out in choice test II (Table 2a). Compared to MSF and the control, significantly $(p<0.05)$ higher percentage of adults $(80.56 \%)$ gravitated towards MBF with $72.78 \%$ accepting it. However, MSF and the control did not differ significantly $(p>0.05)$ in percentage gravitation and acceptance of beetles. 
Table 1a: Main effects of flour type on $T$. castaneum gravitation and acceptance of flour in choice test I

\begin{tabular}{lcc}
\hline Flour type & Percentage gravitation & Percentage acceptance \\
\hline WF & $55.56^{\mathrm{a}}$ & $54.44^{\mathrm{a}}$ \\
MSF & $7.22^{\mathrm{c}}$ & $4.44^{\mathrm{c}}$ \\
MBF & $35.56^{\mathrm{b}}$ & $35.00^{\mathrm{b}}$ \\
Control & $0.56^{\mathrm{c}}$ & $0.56^{\mathrm{c}}$ \\
SEM & 2.8 & 2.6 \\
\hline Mean values in a column followed by the same letter(s) are not \\
significantly different at $p<0.05$ according to Tukey's HSD. \\
WF - wheat flour; MSF -melon seed flour; MBF - mung bean flour; \\
Control -no flour; SEM - standard error of mean
\end{tabular}

Table 1b: Main effects of food deprivation on T. castaneum gravitation and acceptance of flour in choice test I

\begin{tabular}{lcc}
\hline Food deprivation & $\begin{array}{c}\text { Percentage } \\
\text { status of beetles }\end{array}$ & $\begin{array}{c}\text { Percentage } \\
\text { gravitation }\end{array}$ \\
Food deprived & $24.44^{\mathrm{a}}$ & $25.00^{\mathrm{a}}$ \\
Not food deprived & $25.00^{\mathrm{a}}$ & $22.22^{\mathrm{a}}$ \\
SEM & 2.1 & 1.8 \\
\hline Mean values in a column followed by the same letter(s) are not \\
significantly different at $p<0.05$ according to Tukey's HSD. \\
SEM - standard error of mean
\end{tabular}

Table 1c: Interaction of flour type and food deprivation on T. castaneum gravitation/acceptance of flour in choice test I

\begin{tabular}{llcc}
\hline $\begin{array}{l}\text { Flour } \\
\text { type }\end{array}$ & $\begin{array}{l}\text { Food deprivation } \\
\text { status of beetles }\end{array}$ & $\begin{array}{c}\text { Percentage } \\
\text { gravitation }\end{array}$ & $\begin{array}{c}\text { Percentage } \\
\text { acceptance }\end{array}$ \\
\hline WF & Food deprived & $65.56^{\mathrm{a}}$ & $65.56^{\mathrm{a}}$ \\
& Not food deprived & $45.56^{\mathrm{b}}$ & $43.33^{\mathrm{b}}$ \\
MSF & Food deprived & $12.22^{\mathrm{c}}$ & $4.44^{\mathrm{c}}$ \\
& Not food deprived & $12.22^{\mathrm{c}}$ & $4.44^{\mathrm{c}}$ \\
$\mathrm{MBF}$ & Food deprived & $30.00^{\mathrm{b}}$ & $30.00^{\mathrm{b}}$ \\
& Not food deprived & $41.11^{\mathrm{b}}$ & $40.00^{\mathrm{b}}$ \\
Control & Food deprived & $3.12^{\mathrm{d}}$ & $0.00^{\mathrm{c}}$ \\
SEM & Not food deprived & $1.11^{\mathrm{d}}$ & $1.11^{\mathrm{c}}$ \\
\hline
\end{tabular}

Mean values in a column followed by the same letter(s) are not significantly different at $p<0.05$ according to Tukey's HSD. WF - wheat flour; MSF -melon seed flour; MBF - mung bean flour; Control -no flour; SEM - standard error of mean

Likewise, food deprivation on its own did not significantly $(p>0.05)$ affect percentage gravitation and acceptance of adult $T$. castaneum to the flour types in choice test II (Table 2b). Interaction effects of flour types and food deprivation in choice test II (Table 2c) showed significant differences between treatments. Irrespective of their food deprivation status before the test, significantly $(p<0.05)$ more adults gravitated towards $\mathrm{MBF}$ and more also accepted it compared to MSF or the control.

Main effects of flour types (Table 3a) and the main effects of food deprivation (Table $3 b$ ), in nochoice test I, showed that both factors on their own did not have any significant $(p>0.05)$ effect on percentage gravitation of adults to MSF neither did they significantly $(p>0.05)$ affect the percentage of adults that accepted it as food. Also, the interaction effects of flour type and food deprivation in no-choice test I (Table 3c) showed a significantly higher $(p<0.05)$ percentage of adult $T$. castaneum gravitated towards all combinations of MSF and food deprivation levels compared to the control treatments. Conversely, no significant $(p>0.05)$ difference was observed in the percentage of adults that accepted MSF and those which accepted the control at all levels of food deprivation.
Table 2a: Main effects of flour type on $T$. castaneum gravitation and acceptance of flour in choice test II

\begin{tabular}{lll}
\hline Flour type & Percentage gravitation & Percentage acceptance \\
\hline MSF & $11.11^{\mathrm{b}}$ & $5.56^{\mathrm{b}}$ \\
MBF & $80.56^{\mathrm{a}}$ & $72.78^{\mathrm{a}}$ \\
Control & $8.33^{\mathrm{b}}$ & $7.78^{\mathrm{b}}$ \\
S.E.M & 4.3 & 5.9 \\
\hline Mean values in a column followed by the same letter(s) are not \\
Significantly different at $p<0.05$ according to Tukey's HSD. \\
MSF -melon seed flour; MBF - mung bean flour; Control -no flour; \\
SEM - standard error of mean
\end{tabular}

Table 2b: Main effects of food deprivation on T. castaneum gravitation and acceptance of flour in choice test II

\begin{tabular}{lcc}
\hline Food deprivation status & Percentage & Percentage \\
\hline of beetles & gravitation & acceptance \\
Food deprived & $33.33^{\mathrm{a}}$ & $27.78^{\mathrm{a}}$ \\
Not food deprived & $33.33^{\mathrm{a}}$ & $29.63^{\mathrm{a}}$ \\
S.E.M & 3.5 & 4.8 \\
\hline
\end{tabular}

Mean values in a column followed by the same letter(s) are not significantly different at $p<0.05$ according to Tukey's HSD. SEM - standard error of mean

Table 2c: Interaction of flour type and food deprivation on T. castaneum gravitation/acceptance of flour in choice test II

\begin{tabular}{llcc}
\hline $\begin{array}{l}\text { Flour } \\
\text { type }\end{array}$ & $\begin{array}{l}\text { Food deprivation } \\
\text { status of beetles }\end{array}$ & $\begin{array}{c}\text { Percentage } \\
\text { gravitation }\end{array}$ & $\begin{array}{c}\text { Percentage } \\
\text { acceptance }\end{array}$ \\
\hline \multirow{2}{*}{ MSF } & Food deprived & $7.78^{\mathrm{b}}$ & $2.22^{\mathrm{b}}$ \\
& Not food deprived & $14.44^{\mathrm{b}}$ & $8.89^{\mathrm{b}}$ \\
MBF & Food deprived & $91.11^{\mathrm{a}}$ & $81.11^{\mathrm{a}}$ \\
& Not food deprived & $70.00^{\mathrm{a}}$ & $64.44^{\mathrm{a}}$ \\
Control & Food deprived & $1.11^{\mathrm{b}}$ & $0.00^{\mathrm{b}}$ \\
S.E.M & Not food deprived & $15.56^{\mathrm{b}}$ & $15.56^{\mathrm{b}}$ \\
\hline
\end{tabular}

Mean values in a column followed by the same letter(s) are not significantly different at $p<0.05$ according to Tukey's HSD. MSF -melon seed flour; MBF - mung bean flour; Control -no flour; SEM - standard error of mean

Table 4 a presents the main effects of flour type on $T$. castaneum gravitation and acceptance of flour in no-choice test II. The mean percentage gravitation $(81.11 \%)$ and acceptance $(72.22 \%)$ of MBF were significantly higher $(p<0.05)$ than the control. Food deprivation did not however have any significant effect on the mean percentage gravitation and acceptance of MBF by adult $T$. castaneum at $p=0.05$ in no-choice test II (Table $4 b)$. The interaction effects of flour type and food deprivation on $T$. castaneum gravitation and acceptance in no-choice test II is presented in Table 4c. All adults deprived of food gravitated towards MBF in the no-choice test while $93.33 \%$ accepted it. These values were significantly $(p<0.05)$ higher than the observed values of $62.22 \%$ and $51.11 \%$ of adults who were not starved before being offered MBF. Percentage gravitation and acceptance values of treatment combinations involving MBF however differed significantly $(p<0.05)$ from the corresponding values of the control.

Table 5 presents the observed changes in adult and larvae populations of $T$. castaneum in WF, MSF and MBF at one, two and three months after setup (MAS). Mean numbers of adults in WF and MBF were observed to increase from 1 to 2 MAS. 
Table 3a: Main effects of flour type on T. castaneum gravitation and acceptance of flour in no-choice test I

\begin{tabular}{lcc}
\hline Flour type & Percentage gravitation & Percentage acceptance \\
\hline MSF & $65.56^{\mathrm{a}}$ & $24.44^{\mathrm{a}}$ \\
Control & $40.00^{\mathrm{a}}$ & $30.56^{\mathrm{a}}$ \\
SEM & 6.1 & 6.2 \\
\hline \multicolumn{2}{l}{ Mean values in a column followed by the same letter(s) are not } \\
significantly different at $p<0.05$ according to Tukey's HSD. \\
MSF -melon seed flour; Control -no flour; \\
SEM - standard error of mean
\end{tabular}

Table 3b: Main effects of food deprivation on T. castaneum gravitation and acceptance of flour in no-choice test I

\begin{tabular}{lcc}
\hline Food deprivation & Percentage & Percentage \\
\hline status of beetles & gravitation & acceptance \\
Food deprived & $55.66^{\mathrm{a}}$ & $25.56^{\mathrm{a}}$ \\
Not food deprived & $50.00^{\mathrm{a}}$ & $29.44^{\mathrm{a}}$ \\
SEM & 6.1 & 6.2 \\
\hline Mean values in a column followed by the same letter(s) are not \\
significantly different at $p<0.05$ according to Tukey's HSD. \\
SEM - standard error of mean
\end{tabular}

Table 3c: Interaction of flour type and food deprivation on $T$. castaneum gravitation/acceptance of flour in no-choice test I

\begin{tabular}{llcc}
\hline $\begin{array}{l}\text { Flour } \\
\text { type }\end{array}$ & $\begin{array}{l}\text { Food deprivation } \\
\text { status of beetles }\end{array}$ & $\begin{array}{c}\text { Percentage } \\
\text { gravitation }\end{array}$ & $\begin{array}{c}\text { Percentage } \\
\text { acceptance }\end{array}$ \\
\hline MSF & Food deprived & $65.56^{\mathrm{a}}$ & $24.44^{\mathrm{a}}$ \\
& Not food deprived & $65.56^{\mathrm{a}}$ & $24.44^{\mathrm{a}}$ \\
Control & Food deprived & $45.56^{\mathrm{b}}$ & $26.67^{\mathrm{a}}$ \\
SEM & Not food deprived & $34.44^{\mathrm{b}}$ & $34.44^{\mathrm{a}}$ \\
\hline
\end{tabular}

Mean values in a column followed by the same letter(s) are not significantly different at $p<0.05$ according to Tukey's HSD. MSF -melon seed flour; Control -no flour;

SEM - standard error of mean

Table 4a: Main effects of flour type on T. castaneum gravitation and acceptance of flour in no-choice test II

\begin{tabular}{lcc}
\hline Flour type & Percentage gravitation & Percentage acceptance \\
\hline MBF & $81.11^{\mathrm{a}}$ & $72.22^{\mathrm{a}}$ \\
Control & $7.78^{\mathrm{b}}$ & $7.78^{\mathrm{b}}$ \\
SEM & 8.4 & 6.5 \\
\hline
\end{tabular}

Mean values in a column followed by the same letter(s) are not significantly different at $p<0.05$ according to Tukey's HSD. MBF -mung bean flour; Control -no flour;

SEM - standard error of mean

Table 4b: Main effects of food deprivation on $T$. castaneum gravitation and acceptance of flour in no-choice test II

\begin{tabular}{lcc}
\hline $\begin{array}{l}\text { Food deprivation } \\
\text { status of beetles }\end{array}$ & $\begin{array}{c}\text { Percentage } \\
\text { gravitation }\end{array}$ & $\begin{array}{c}\text { Percentage } \\
\text { acceptance }\end{array}$ \\
\hline Food deprived & $50.00^{\mathrm{a}}$ & $46.67^{\mathrm{a}}$ \\
Not food deprived & $38.89^{\mathrm{a}}$ & $33.33^{\mathrm{a}}$ \\
SEM & 8.4 & 6.5 \\
\hline
\end{tabular}

Mean values in a column followed by the same letter(s) are not significantly different at $p<0.05$ according to Tukey's HSD. SEM - standard error of mean

Table 4c: Interaction of flour type and food deprivation on $T$. castaneum gravitation/acceptance of flour in no-choice test II

\begin{tabular}{llcc}
\hline \multirow{2}{*}{ Flour type } & $\begin{array}{l}\text { Food deprivation } \\
\text { status of beetles }\end{array}$ & $\begin{array}{c}\text { Percentage } \\
\text { gravitation }\end{array}$ & $\begin{array}{c}\text { Percentage } \\
\text { acceptance }\end{array}$ \\
\hline \multirow{2}{*}{ MBF } & Food deprived & $100.00^{\mathrm{a}}$ & $93.33^{\mathrm{a}}$ \\
& Not food deprived & $62.22^{\mathrm{b}}$ & $51.11^{\mathrm{b}}$ \\
Control & Food deprived & $0.00^{\mathrm{c}}$ & $0.00^{\mathrm{c}}$ \\
SEM & Not food deprived & $15.56^{\mathrm{c}}$ & $15.56^{\mathrm{c}}$ \\
& & 11.9 & 9.2 \\
\hline Mean values in a column followed by the same letter(s) are not \\
significantly different at $p<0.05$ according to Tukey's HSD. \\
MBF -mung bean flour; Control -no flour; SEM - standard error of mean
\end{tabular}

In contrast, the number of adult $T$. castaneum decreased slightly in MSF between the periods. Also, larval population in WF and MBF sharply decreased at 2 MAS and thereafter gradually increased at 3 MAS. Larval populations in MSF, however, continued to decrease gradually at 3 MAS. At each month after setup, significantly $(p<0.05)$ more adults and larvae were recorded in WF than in the other two flour types. The numbers of adults and larvae in MSF and MBF were similar $(p>0.05)$ at 1 MAS, significantly $(p<0.05)$ higher in MBF compared with MSF at 2 and 3 MAS.

Nutritional composition of WF, MSF and MBF determined through proximate analysis is presented in Table 6. The MSF had the highest percentage crude protein $(21.81 \%)$, percentage ether extract (15.90) and percentage crude fibre $(46.32 \%)$ values, while WF had the lowest percentage crude protein $(6.08 \%)$ and percentage crude fibre $(4.40 \%)$ values. The lowest percentage ether extract value $(9.57 \%)$ was however recorded in mung bean flour. There was a significant difference $(p<0.05)$ between the highest and lowest values of percentage crude protein, ether extract and crude fibre. The highest percentage nitrogen free extract value $(64.17 \%)$ was observed in WF while MSF had the lowest percentage nitrogen free extract $(4.60 \%)$ content. For this parameter, MBF with $49.92 \%$ had an intermediate value that was significantly $(p<0.05)$ different from the highest and lowest values.

\section{DISCUSSION}

In this study, adult $T$. castaneum accepted a given flour type by settling into it after probing its surface for suitability as a host. The beetles were also observed to preferentially gravitate towards and accept WF in choice tests involving all three flour types. This clearly demonstrates the preference of $T$. castaneum adults for the food host on which they were raised if given the choice (Jang et al., 1982). Furthermore, in the absence of WF, MBF was preferred over MSF depicting the ability of the rust red flour beetle to infest a wide range of suitable food hosts (Campbell and Runnion, 2003; Wong and Lee, 2011) even when they are unfamiliar. While food deprivation did not seem to influence the selection or preference of MBF or MSF by adult beetles, it was observed to influence selection of WF in the present study with more adults gravitating to and accepting the flour when starved. This observation agrees with BartonBrowne and Withers (2002) who reported that increasing host deprivation period will in turn increase the probability of host acceptance in insects. It however also indicates the inferiority of food deprivation to prior feeding experience as a factor influencing flour selection by the rust red flour beetle. Thus food deprivation is unlikely to influence beetles' selection of a given flour type if they have not previously fed on the flour. 
Table 5: Population dynamics of T. castaneum on the wheat, melon seed and mung bean flours over three months

\begin{tabular}{|c|c|c|c|c|c|c|}
\hline Flour & \multicolumn{3}{|c|}{ Mean number of adults } & \multicolumn{3}{|c|}{ Mean number of larvae } \\
\hline type & $1 \mathrm{MAS}$ & 2 MAS & 3 MAS & $1 \mathrm{MAS}$ & 2 MAS & $3 \mathrm{MAS}$ \\
\hline WF & $95.00^{\mathrm{a}}$ & $195.33^{\mathrm{a}}$ & $211.33^{\mathrm{a}}$ & $109.67^{\mathrm{a}}$ & $77.00^{\mathrm{a}}$ & $81.33^{\mathrm{a}}$ \\
\hline MSF & $30.33^{b}$ & $27.00^{\mathrm{c}}$ & $28.33^{\mathrm{c}}$ & $45.00^{\mathrm{b}}$ & $8.67^{\mathrm{c}}$ & $7.67^{\mathrm{c}}$ \\
\hline MBF & $26.67^{b}$ & $82.67^{\mathrm{b}}$ & $87.67^{\mathrm{b}}$ & $76.33^{\mathrm{b}}$ & $26.00^{\mathrm{b}}$ & $31.00^{\mathrm{b}}$ \\
\hline SEM & 11.4 & 24.9 & 28.0 & 14.0 & 12.0 & 14.9 \\
\hline
\end{tabular}

Mean values in a column followed by the same letter(s) are not significantly different at $p<0.05$ according to Tukey's HSD.

WF - wheat flour; MSF -melon seed flour; MBF - mung bean flour; Control -no flour; SEM - standard error of mean; MAS - months after setup

Table 6: Nutritional composition of wheat, melon seed and mung bean flours

\begin{tabular}{|c|c|c|c|c|c|c|}
\hline Flour type & $\begin{array}{c}\text { Moisture } \\
(\%)\end{array}$ & $\begin{array}{c}\text { Crude Protein } \\
(\%)\end{array}$ & $\begin{array}{c}\text { Ether Extract } \\
(\%)\end{array}$ & $\begin{array}{l}\text { Ash } \\
(\%)\end{array}$ & $\begin{array}{c}\text { Crude Fibre } \\
(\%)\end{array}$ & $\begin{array}{c}\text { Nitrogen Free Extract } \\
(\%)\end{array}$ \\
\hline WF & $11.24^{\mathrm{a}}$ & $6.08^{c}$ & $12.30^{\mathrm{b}}$ & $1.80^{\mathrm{c}}$ & $4.40^{\mathrm{c}}$ & $64.17^{\mathrm{a}}$ \\
\hline MSF & $8.51^{\mathrm{b}}$ & $21.81^{\mathrm{a}}$ & $15.90^{\mathrm{a}}$ & $2.85^{\mathrm{b}}$ & $46.32^{\mathrm{a}}$ & $4.60^{\mathrm{c}}$ \\
\hline $\mathrm{MBF}$ & $9.89^{\mathrm{ab}}$ & $16.08^{b}$ & $9.57^{\mathrm{c}}$ & $4.27^{\mathrm{a}}$ & $10.26^{\mathrm{b}}$ & $49.92^{\mathrm{b}}$ \\
\hline SEM & 0.45 & 2.29 & 0.92 & 0.37 & 6.56 & 8.99 \\
\hline
\end{tabular}

Mean values in a column followed by the same letter(s) are not significantly different at $p<0.05$ according to Tukey's HSD.

WF - wheat flour; MSF -melon seed flour; MBF - mung bean flour; Control -no flour; SEM - standard error of mean; MAS - months after setup *obtained by subtracting the preceding contents from $100 \%$

Also, in this study, higher populations were recorded in WF at each month of observation showing that the flour was better utilized by $T$. castaneum for growth/development compared to the other flour types. While prior feeding experience of parent beetles with WF may have contributed to the reduced adult populations in MBF and MSF at the 1 MAS, adult populations in both flour types at 2 and 3 MAS clearly indicate the influence of some other factors on flour utilization by $T$. castaneum.

Nutritional value of flour types may be the most important factor influencing selection and utilization by $T$. castaneum since nutrient-taking seems to be the primary reason for infesting and colonizing the host flour in the first place (Campbell and Hagstrum, 2002; Wong and Lee, 2011). Indeed, the important roles of nutritional composition in the selection and utilization of flour types by insects have been reported by several authors (Jang et al., 1982; Kayode et al., 2014; Yan et al., 2017; AsiyanbiHammed and Simsek, 2018). This primary need to feed probably influenced the acceptance of MBF and, to a lesser degree, of MSF over the control in this study despite being unfamiliar hosts. Flour utilization for growth by $T$. castaneum thus seems to be determined mainly by flour nutritional composition and not by prior feeding experience.

The nitrogen free extracts from carbohydrates may be regarded as the most essential nutrients in seeds because they represent the primary source of metabolic energy (Kayode et al., 2014; Adesina, 2018; Anonymous, 2019). The development of flour beetles, for example, is influenced by carbohydrate concentrations in diets such that optimal growth occurs when concentration is about $70 \%$ while beetles fail to develop at concentrations below $40 \%$ (Behmer, 2006). This probably explains why WF and MBF, with over $40 \%$ nitrogen free extract content, both supported an increase in $T$. castaneum populations in the present study. In contrast, MSF, with low carbohydrate, least supported population growth of the rust red flour beetle. High fat content in the absence of carbohydrate sources has also been reported to inhibit the growth rate of $T$. castaneum larvae (Applebaum, 1969). It may thus be inferred from the foregoing that the presence of high fat and low carbohydrate contents inhibited the satisfactory utilization of MSF for growth and development by the rust red flour beetle in the present study.

\section{CONCLUSION}

Prior feeding experience of $T$. castaneum influenced the selection of WF in this study and may pose a bias in choice tests. This bias may however be removed by raising $T$. castaneum on a suitable flour type which will not be included as a treatment in proposed tests. The influence of food deprivation on flour selection was also shown to be subject to prior feeding experience in the present study. In contrast, utilization of flour types by $T$. castaneum was not influenced by prior feeding experience or food deprivation in this study. Information provided in this study will enhance the reliability of results from host range studies of stored product insects.

\section{REFERENCES}

Adesina S.A. (2018). Effect of processing on the proximate composition of sunflower (Helianthus Annuus) seeds. Agro-Science, 17 (3), 27-33. DOI: https://dx.doi.org/10.4314/as.v17i3.5

Anonymous (2019). Proximate composition and detergent fibre http://www.famic.go.jp/ffis/oie/ obj/nutrients.pdf. Accessed on 07 July 2019

AOAC (2010). Official Methods of Analysis (19th ed.). Association of Official Analytical Chemists. Washington DC

Applebaum S.W. (1969). The suitability of groundnuts for the development of Tribolium castaneum (Herbst) (Coleoptera, Tenebrionidae). J. Stored Products Res., 5 (4), 305-310. DOI: 10.1016/0022-474x(69)90004-6

Asiyanbi-Hammed T.T. and Simsek S. (2018). Comparison of physical and chemical properties of wheat flour, fermented yam flour, and unfermented yam flour. J. Food Processing \& Preservation, e13844. DOI: $10.1111 /$ jfpp. 13844 
Barton-Browne L. and Withers T.M. (2002). Timedependent changes in the host-acceptance threshold of insects: implications for host specificity testing of candidate biological control agents. Biocontrol Sci. Technol., 12, 677-693

Behmer S.T. (2006). Insect dietary needs: plants as food for insects. In: R.M. Goodman (ed.), Encyclopedia of Plant and Crop Science (pp. 1-4). Marcel Dekker Publishers, New York, NY

Bernays E.A. and Chapman R.F. (1994). Host-plant selection byPhytophagous insects, Chapman and Hall, London, p. 312

Bulus S.D. (2008). Studies on Millet, Acha and Wheat: Their Nutrient Composition and Their Susceptibility to Tribolium castaneum (Herbst). M.Tech. Thesis in the Department of Biology, Federal University of Technology, Akure

Campbell J.F. and Hagstrum D.W. (2002). Patch exploitation by Tribolium castaneum: movement patterns, distribution and oviposition. J. Stored Prod. Res., 38, 55-68

Campbell J. F. and Runnion C. (2003). Patch exploitation by female red flour beetles, Tribolium castaneum. $J$. Insect Sci., 3, 1-8

Hill D.S. (1983). Agricultural Insect Pests of the Tropics and Their Control $\left(2^{\text {nd }}\right.$ ed.), Cambridge University Press, Cambridge, p. 746

Jang E.B., Lin C.S. and Mitchell W.C. (1982). Food preference of seven stored product insects to dried processed taro products. Proceedings of Hawaiian Entomological Society, 24 (1), 97-107

Johnson J. (2013). Pest control in postharvest nuts. In: L.J Harris (ed.), Improving the Safety and Quality of Nuts, Woodhead Publishing Limited, Philadephia, USA, pp. 56-79

Kayode O.Y., Adedire C.O. and Akinkurolere R.O. (2014). Influence of four cereal flours on the growth of Tribolium castaneum Herbst (Coleoptera: Tenebrionidae). Ife J. Sci., 16 (3), 505 - 516

Lale N.E.S. and Yusuf B.A. (2001). Potential of varietal resistance and Piper guineense seed oil to control infestation of stored millet seeds and processed products by Tribolium castaneum (Herbst). J. Stored Prod. Res., 37, 63-75
Tamgno B.R. and Ngamo-Tinkeu S.L. (2014). Application of the flour of four leguminous crops for the control of tenebrionidae beetle (Tribolium castaneum-Herbst). Afr. J. Food, Agric., Nutr. Dev., 14 (1), 8474-8487

Schaffner U. (2001). Host range testing of Insects for biological weed control: how can it be better interpreted? BioScience, 51 (11), 951

Shafique M., Ahmad M. and Chaudry M.A. (2006). Feeding preference and development of Tribolium castaneum (Herbst.) in wheat products. Pakistan J. Zoology, 38 (1), 27-31

Van Driesche R.G. and Murray T.J. (2004). Overview of testing schemes and designs used to estimate host ranges. In: Van Driesche R.G. and Reardon R. (eds.), Assessing Host Ranges for Parasitoids and Predators used in Classical Biological Control: A Guide to Best Practice (pp. 68-89). USDA Forest Service, Morgantown, West Virginia, U.S.A

Villaverde M.L., Juárez, M.P., and Mijailovsky S. (2007). Detection of Tribolium castaneum (Herbst) volatile defensive secretions by solid phase microextraction-capillary gas chromatography (SPME-CGC). J. Stored Prod. Res., 43 (4), 540-545. DOI: 10.1016/j.jspr.2007.03.003

Withers R.T. and Mansfield S. (2005). Choice or nochoice tests? Effects of experimental design on the expression of host range. Second International Symposium on Biological Control of Arthropods, pp. 620-633

Wong N. and Lee C.Y. (2011). Relationship between population growth of the red flour beetle Tribolium castaneum and protein and carbohydrate content in flour and starch. J. Economic Entomol., 104 (6), 20872094. DOI: http://dx.doi.org/10.1603/EC11234

Yan Y., Williams S. B., Murdock L. L. and Baributsa D. (2017). Hermetic storage of wheat and maize flour protects against red flour beetle (Tribolium castaneum Herbst). PLoS ONE 12 (9), e0185386. DOI: 10.1371/JOURNAL.PONE.0185386 